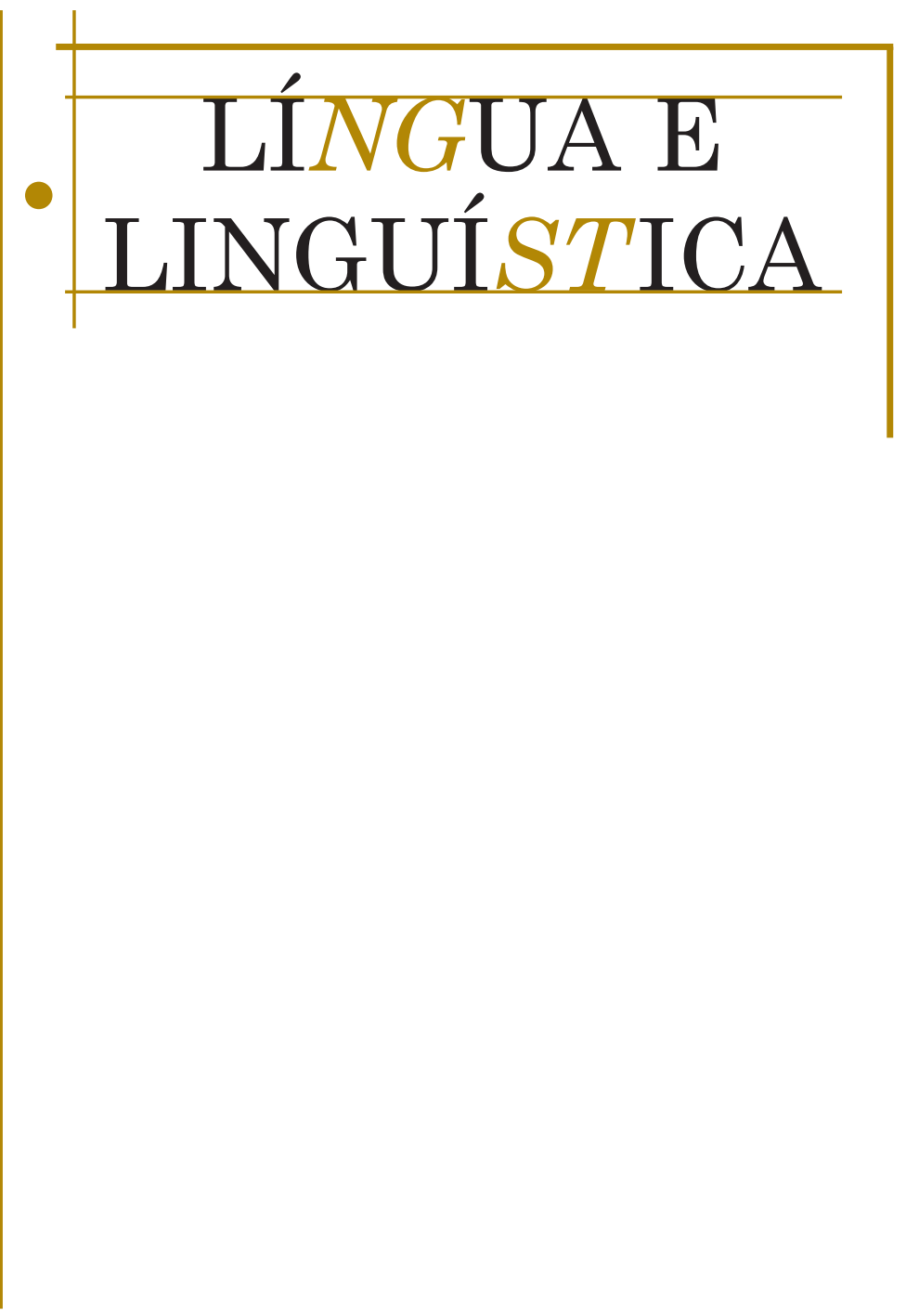




\section{O MUNDO \\ LUSO-AFRO-BRASILEIRO DE MARIA ARCHER: UM OLHAR SOBRE BRASIL, FRONTEIRA DA ÁFRICA}

\section{Márcio Matiassi Cantarin* Naira de Almeida Nascimento* *}

Resumo: Este ensaio pretende observar como o discurso da escritora Maria Archer (1899-1982), uma mulher fora do padrão esperado para a mulher portuguesa do Estado Novo, promove ora a manutenção, ora rupturas com a visão e a política imperialista do regime salazarista nas colônias do ultramar, ademais contribuindo para a construção do imaginário sobre a África, em Portugal e no Brasil. Em particular, será dado destaque às formas como a escritora percebe e analisa a presença da mulher na paisagem social de Angola e Moçambique, a partir do livro Brasil, fronteira da África, de 1963.

Palavras-chave: Maria Archer. Brasil, fronteira da África. Literatura colonial.

A minha obra literária tem sido norteada pelo princípio vital de rebater o conceito arcaico da inferioridade mental da mulher (ARCHER, 1952, p. 5).

\section{INTRODUÇÃO}

"N ão é de hoje que as agendas do feminismo e do pós-colonialismo comungam de um discurso que as aproxima. Também não é novidade que resguardam especificidades. Mesmo no seio dos movimentos feministas, podem-se verificar demandas muito diversas, como no caso do direito da mulher decidir sobre o aborto, discussão premente para as feministas europeias ou da América do Norte e que se torna de menor urgência quanto mais se avança em direção a latitudes ao sul.

\footnotetext{
* Universidade Tecnológica Federal do Paraná (UTFPR) - Curitiba - PR - Brasil. E-mail: cantarin@gmail.com

** Universidade Tecnológica Federal do Paraná (UTFPR) - Curitiba - PR - Brasil. E-mail: naira.alm@gmail.com
} 
Se admitirmos que o discurso colonial/fascista e o patriarcal/machista são alinhavados com o mesmo fio, poderemos aceitar facilmente a assertiva de Du Plessis (1985, p. 46) de que "a mulher da colônia é metáfora da mulher como colônia"1, o que faz dela uma "duplamente colonizada", ou "duplamente deslocada", para usar os termos de Spivak (1994, p. 191), obrigando-a a "percorrer um caminho duplo: o da sua emancipação e o da libertação de todo o país" (MANCEAUX, 1976, p. 77). Isso posto, será lícito aceitarmos a proposição do escritor queniano Ngugi Wa Thiongo (apud BONNICI, 2000, p. 157) sobre a "impossibilidade de libertação cultural sem a libertação feminina", complementar à afirmação de Thomas Bonnici (2000, p. 158) de que "Uma estratégia da libertação feminina nos países pós-coloniais parece ser a descolonização da cultura".

É a partir deste ponto que lançaremos um olhar sobre a produção da portuguesa Maria Archer, em particular sobre o seu Brasil, fronteira da África, publicado em 1963. O intuito é observar o quanto o discurso dessa escritora fora do padrão esperado para a mulher portuguesa de sua época promove ora a manutenção, ora rupturas com a visão e a política imperialista do Estado Novo português, ademais contribuindo com a construção do imaginário sobre a África, no Brasil e em Portugal.

\section{TRÂNSITOS}

A literatura em Portugal projetou alguns nomes de mulheres com grande destaque a partir dos anos 1940 do século passado, como Agustina Bessa-Luis, Lídia Jorge, as "três Marias", entre outras. No entanto, à Maria Archer se reserva certo ostracismo que merece ser revisto em face da vasta produção da autora a partir de meados da década de 1930. A relação entre a dificuldade para uma mulher publicar e a extensa bibliografia de Archer constitui, por si só, um chamariz para que a crítica acadêmica detenha seu olhar de um modo mais acurado sobre a autora.

Nascida em Lisboa em 1899, a escritora viveu 14 anos na África, entre idas e vindas à metrópole, ora acompanhando os pais em Moçambique, Guiné e Angola, ora de regresso a Moçambique acompanhando o marido, do qual se divorciaria em 1931. O ambiente hostil em Portugal para aqueles que se opunham ao regime de Salazar fez com que Maria Archer se exilasse no Brasil em 1955, de onde continuou empreendendo esforços de resistência ao regime vigente em Portugal.

Em meio a escritos que foram de novelas sentimentais, como em Três mulheres, seu livro de estreia, a um livro destinado ao público infantojuvenil, ganha destaque um tipo de literatura voltada para a temática africana, em que pese o "contexto social propício à produção, circulação e recepção de textos, ficcionais e não-ficcionais, sobre o 'Império Colonial Português”' (MARTINS, 2005, p. 78). Deve-se assinalar que o período reuniu as condições necessárias à produção e ao consumo de livros com a temática colonial, alavancada tanto pelo gosto do público pelo exotismo quanto pela necessidade do regime de se afirmar como força civilizadora nos trópicos. Tal estratégia era mesmo incentivada por um Concurso de Literatura Colonial, promovido pela Agência Geral das Colônias,

1 No original: "a woman from a colony is a trope for the woman as a colony". 
numa nítida ofensiva ideológica do governo para criar internamente o que chamava de cultura ou "mentalidade imperial".

Nesse ínterim, entre vários livros com a temática colonial, Archer emplaca seis volumes na coleção Cadernos Coloniais (entre 1936 e 1938). Perfeitamente adaptada à necessidade do tempo, a coleção voltava-se para a "descrição de paisagens, usos e costumes indígenas e a narração de episódios da história colonial portuguesa, invariavelmente associados a figuras masculinas" (MARTINS, 2005, p. 82). Não é preciso dizer que a maioria esmagadora dos 70 cadernos publicados é de autoria de homens; Archer foi a única mulher a publicar na coleção. Leonor Pires Martins (2005, p. 80-81) ressalta que mais importante do que o fato de uma mulher exercer a literatura é a estratégia enunciativa subversiva utilizada por Archer ao descentralizar discursos que "destacaram as acções de figuras masculinas e elidiram, ou pelo menos marginalizaram, a participação das mulheres".

São esses cadernos que formam a base de Brasil, fronteira da África, publicado em São Paulo em 1963, e que possui um tom de libelo ao conclamar que o Brasil assuma o "posto de paladino da nossa língua e da nossa cultura na África de expressão portuguesa" (ARCHER, 1963, p. 8), posto este que a autora acredita ter sido perdido pelo Portugal imperialista de Salazar. Já no prefácio da obra, impõe-se um discurso antissalazarista que incita as nações africanas, em particular Angola, a se espelhar no Brasil, nação soberana saída do colonialismo português. Explica ainda, numa espécie de busca pela cumplicidade do colonizado, que também o povo português é vítima do regime. É como se a autora estivesse definindo seu locus de "colonizadora de boa vontade" (MEMMI, 1977). Ainda no prefácio, e de maneira mais agressiva, se insurge e ataca o governo fascista português (ao qual chama de "gang colonialista de Salazar"), o qual afirmara, por meio de seu Cônsul no Brasil que "à mulher africana não é atribuída a dignidade de pessoa humana" (ARCHER, 1963, p. 7).

Misto de história e literatura de viagem, o leitor pode depreender do livro a visão de uma mulher portuguesa (fora do padrão, é bem verdade) acerca da dinâmica do processo de colonização empreendido por Portugal na África, nomeadamente em Angola e Moçambique e com ênfase no período em que a presença do colonizador se tornou mais ostensiva. O próprio tom de literatura de impressões de viagem que, por vezes, o texto de Archer adquire assume um caráter desconstrutor, uma vez que esse é um gênero literário que permanece, histórica e culturalmente, ancorado à identidade de gênero masculina, uma vez que supõe a experiência do deslocamento, considerada pouco apropriada para a mulher.

Sabe-se que as sequelas deixadas tanto nas colônias quanto na metrópole pela chamada guerra do ultramar ainda estão a ser elaboradas pelo imaginário dos povos envolvidos e constituem um motivo frequente na literatura de expressão portuguesa contemporânea. Tais traumas afetam, de modo particular, as mulheres, as da colônia (duplamente) e as da metrópole, em seu papel de esposamãe-filha de militar ausente, ou ainda de esposa que acompanha o marido aos "cus de Judas", parafraseando Lobo Antunes, e que abrem mão de seus sonhos e anseios para atender ao impeto capitalista de seus companheiros. Compreender como a mulher retrata e é retratada em um momento imediatamente anterior à irrupção da guerra colonial pode lançar alguma luz sobre os subterfúgios utilizados por essas mulheres para elaborarem os traumas que deram a tônica da ocupação portuguesa na África, a despeito de algum discurso luso-tropicalista 
que, a exemplo do Brasil, possa insinuar a harmonia existente entre colonizador e colonizado. Outrossim, é possivel perscrutar, em meio a um discurso ainda um tanto mistificador, uma voz que parecia compreender que a libertação das colônias se faria em uníssono com a libertação da mulher portuguesa do jugo masculino, bem como da libertação do país do jugo do regime fascista de Oliveira Salazar, na esteira das ideias de Ngugi, citadas anteriormente.

Com esse intuito, nosso olhar se deterá no capítulo "V - Presença da mulher na paisagem social da África portuguesa" (ARCHER, 1963, p. 121-166), justamente um capítulo inédito, que não fizera parte da coleção dos Cadernos Coloniais, tendo sido incorporado apenas na edição compilada no Brasil em 1963.

Um pormenor de relevo para as análises de Brasil, fronteira da África está no fato de que, originalmente, os cadernos foram publicados entre 1936 e 1938 , reunindo análises a partir das impressões pessoais da autora desde 1910 (ano de seu primeiro contato, ainda menina, com a África). No entanto, no ato dessa compilação/reelaboração, mais de 20 anos depois, a escritora já sofrera as perseguições da Polícia Internacional e de Defesa do Estado (Pide), que fizeram com que se exilasse no Brasil, e já havia sido deflagrada a chamada "guerra colonial". Tal distanciamento imprime ao seu discurso um tom mais engajado e crítico da experiência vivida, com laivos de manifesto antissalazarista algures no texto, além de um ataque direto e incisivo no prefácio.

\section{Permanências e Rupturas}

A primeira constatação dessa "autora testemunha" diz respeito à pequena influência da mulher branca na paisagem social da África, em razão oposta ao que aconteceu no Brasil, fenômeno que Maria Archer (1963, p. 121) atribui ao caráter diverso que a empresa colonizadora teve na África e não à "inaptidão civilizadora" da mulher portuguesa, uma vez que esta já havia demonstrado sua presença forte e decisiva na "gestação da civilização brasileira". Já de saída, como se nota, a escritora dá o tom que revela a ideologia da superioridade europeia em sua missão civilizadora, em que pese o papel fundamental da mulher na consolidação do que foi conquistado inicialmente pelo homem:

Certo é que as grandes linhas históricas da humanidade têm sido, inicialmente, traçadas pelos homens, mas é forçoso reconhecer que, na consolidação dessa obra, no afeiçoamento da terra conquistada, na gênese dos costumes, na criação do regionalismo, a interferência da mulher foi e é necessária, e que ela, e só ela, é capaz de introduzir num País novo o equilíbrio entre o moral e o social, a polidez que suavisa o trato diário, a arte doméstica, a graça do luxo, as inutilidades que encantam a vida, enfim, os elementos que transformam a terra selvagem em terra pátria e a consolidam pela alegria de viver (ARCHER, 1963, p. 129).

Não se trata aqui de julgar o discurso de Maria Archer pelo que se incorreria em anacronismo, antes, o que se pretende, é verificar onde se insinuam rachaduras em tal discurso e que adiante promoverão seu completo desmoronamento (o que se poderá verificar em um Novas cartas portuguesas, para citar apenas um exemplo mais notório).

$\mathrm{Na}$ esteira do luso-tropicalismo freyreano (aliás, o mestre de Apipucos não poupava elogios à autora portuguesa), Archer (1963, p. 123) irá atribuir ao limi- 
tado número de mestiços, uma vez que não teria havido simbiose do elemento lusitano com a terra, a falta de "originalidade cultural" em Angola e Moçambique. Ainda a ausência da estrutura senhorial que se verificava no nordeste brasileiro com "casa e capela" (ARCHER, 1963, p. 123) será apontada como símbolo do caráter anticivilizador que a colonização portuguesa legou àqueles países.

No que diz respeito à hierarquia social entre os negros em Angola, é sintomático o trecho no qual se relata que o nativo: "Se é educado em centros civilizados, como Luanda, e com costumes portugueses, o indigena prefere um terno de casimira, mas a sua mulher ou filha ainda usam os panos enrolados no corpo, traje vulgar em toda a África" (ARCHER, 1963, p. 126).

O excerto pode bem ser lido em mais de uma perspectiva. Fôssemos otimistas poderiamos crer que a mulher resiste à europeização e permanece como guardiã de seus usos e costumes, expressos pelo uso da vestimenta tradicional. Quando não, pode-se depreender que à mulher angolana (como à mulher em todas as sociedades) não é conferido o mesmo status que ao homem, não sendo a elas facultadas as mesmas condições para a assimilação dos costumes portugueses. A exceção vem confirmar a regra: nas ocasiões em que a politica de Portugal concedeu algum poder à mulher, como no caso da concessão dos "prazos" às Donas do Zambeze, estas passaram a ostentar roupas e luxos das Índias e, posteriormente, quando já decadentes, a vestirem-se "ao gosto português" (ARCHER, 1963, p. 139-140). Há que ressaltar que essa política de concessão de terras às mulheres no século XIX não constituía qualquer intenção de empoderamento feminino (embora as "prazeiras" tenham gozado de grande prestígio e influência), foi antes um modo encontrado por Dona Maria II, princesa do Brasil que então reinava em Portugal, para aliciar os reinóis a permanecerem na colônia, uma vez que as mulheres proprietárias (em geral mestiças) só adquiriam o título de posse da terra se casassem com portugueses. Aqui se nota o que Spivak chama de dupla colonização da mulher.

Ora, a situação da mulher mestiça era mais suportável, nomeadamente após a quarta geração. Essa mulher, segundo a autora, era o tipo mais belo e raro e, conforme a situação financeira do pai, facilmente encontrava casamento com brancos, estudava em Lisboa ou Coimbra e comungava dos "ideais da mulher europeia moderna" (ARCHER, 1963, p. 144). O mesmo não se podia dizer da mulher negra:

De aspecto, a mulher primitiva, adulta, é feia. Carnes flácidas, fortemente deformadas pelas maternidades, dentes irregulares [...] Pernas secas, de musculatura masculina, coxas magras, pés chatos, grandes ventres pregueados, seios como tetas de animal leiteiro [...] A vida maltrata-a desde a puberdade (ARCHER, 1963, p. 129).

No trecho, tem-se a melhor ilustração para a afirmação de Simone de Beauvoir (1980) sobre a mulher ser a vitima da espécie. Mas, para além do fator biológico, impõe-se o peso da cultura patriarcal, o que também faz dela uma vítima da engenharia social:

A lei consuetudinária, único direito dos negros selvagens, poucos privilégios concede à mulher. Dá-lhe a posse dos filhos do casal [...], e permite-lhe que, em solteira, pratique a liberdade amorosa. Após o casamento torna-se propriedade do marido, objeto de uso exclusivo do marido, e só com o consentimento dele e proveito econômico para êle podem praticar o adultério (ARCHER, 1963, p. 130). 
Pesa, por fim, sobre a mulher negra a crença em sua inépcia mental: "A sua grei considera-a tão pobre de inteligência que só a julga apta para o trabalho doméstico e a lavoura" (ARCHER, 1963, p. 130), de modo que a arte era prerrogativa dos homens da tribo. Mesmo em caso de tribos com linha hereditária matrilinear (a exemplo de grupos indígenas brasileiros ou da Oceania), "Muito raramente, e só em casos de realeza ou feitiçaria, a mulher indigena influi na vida política de seu povo" (ARCHER, 1963, p. 130).

A obrigação entre os bantu de a mulher ser responsável pela lavoura será reafirmada pela politica salazarista, pelo que se pode perceber o alinhamento providencial entre o regime colonial (externo) e a estrutura patriarcal tradicional (interna); o elo mais fraco, quem trabalha de graça, é sempre a mulher:

A regulamentação do trabalho indigena, nas colônias portuguesas da África, obriga o negro a assalariar-se nas fazendas dos brancos seis meses por ano. A mulher negra, porém, está legalmente impedida de trabalhar nas fazendas dos brancos, em serviços agricolas ou industriais. Fica feita, automaticamente, uma certa divisão do trabalho, forçado o homem a colaborar na organização capitalista da colônia e a lavoura indígena provida de braços femininos, que são o sustento da família (ARCHER, 1963, p. 133).

Na sequência, a autora discorre sobre outras categorias de mulher indígena, aquelas que tiveram acesso, de algum modo, a politicas de assimilação, para concluir que: "Contudo a sua importância, como expoente da civilização introduzida nos trópicos pelos portugueses, não é valiosa”, e ainda:

É necessário que, ou através da escola ou de organismos para escolares, se faça um esforço no sentido de completar a educação desta humanidade desajustada, de equilíbrio moral perturbado, de transição social mal estabelecida (ARCHER, 1963, p. 137).

Um pormenor ao qual não podemos nos furtar: se há mestiços, por via de regra, eles são frutos do conúbio entre homem branco e mulher negra, "Raríssimo, porém, extremamente raro e sensacional, é o caso de casamento de branca com negro ou mulato" (ARCHER, 1963, p. 138), pelos motivos que Franz Fanon (1975, p. 53) elucidou ao analisar o romance autobiográfico Je suis Martiniquaise, de Mayotte Capécia. Perfeitamente compreensivel no quadro da cultura patriarcal portuguesa, mas que não deixa de ser mais um índice da falta de paridade entre homem e mulher, sejam negros ou brancos, seja na colônia ou na metrópole.

Certa feita, Machado de Assis disse que "Libertado o negro" restaria "libertar o branco". Pensamos que o espírito dessa frase está refletido em um trecho de Brasil, fronteira da África, no qual Maria Archer abandona o seu discurso "quase científico", segundo as palavras de Gilberto Freyre (1954?, p. 10), para adotar uma narrativa ficcionalizada a fim de expor a situação de duas classes de mulheres brancas na colônia: 1 . as que se sujeitaram a viver com seus maridos em rincões isolados e sem qualquer resquício das comodidades que a Europa oferecia; e 2. aquelas que constituiam o jet set de Luanda.

Após as considerações de viés antropológico e etnológico, revela-se a romancista que enceta algumas páginas ficcionais como que para exemplificar o que acabara de expor. Em um tom de sociologia que tende ao naturalismo demonstra sua empatia para com essa mulher pobre e suas parcas chances de liberta- 
ção e felicidade. Conta a vida de portuguesas que viveram em ermos a mais de 100 quilômetros "do próximo povoado habitado por brancos" (ARCHER, 1963, p. 145), as dificuldades encontradas para educarem os filhos longe da influência da cultura dos nativos, isso sem qualquer referencial palpável da cultura portuguesa. Narra ainda a dificuldade de cultivar uma horta nos trópicos para que os filhos tivessem alimento fresco e o medo dos ataques de animais selvagens ou de cupins, mas, principalmente, a depressão pela tristeza, solidão e saudades de Portugal e de sua gente, um "banzo branco" por assim dizer.

Tal qual aquela Piedade de Jesus d'O Cortiço, a mulher portuguesa emigrada sofre com o "desconforto do clima moral" e a "hostilidade do ambiente social" de meios "eivados de hierarquias burocráticas, de desniveis sociais e sem espaço vital para a alegria da classe média" (ARCHER, 1963, p. 154). "[...] o trabalho mal pago, o clima depauperante, a vida acanhada no lar, a falta de distração inerente aos meios pequenos, de certo modo a desesperança, cedo estiolam a saúde e o ânimo dessas emigradas" (ARCHER, 1963, p. 154, grifo nosso). Falta, pois, qualquer esperança para essa branca pobre, para quem Maria Archer parece reclamar o espírito daquela frase machadiana.

Fica a situação agravada quando essa mulher branca se enquadra no estatuto de "não genuína", ou seja, aquelas já nascidas em África e que, do ponto de vista cultural são consideradas pela autora "genitos estiolados das raças europeias" devido ao fato de serem criadas em um ambiente inalcançável pela cultura de seus pais e avós:

Criadas nos meios pobres, pobres em sentido cultural, das nossas colônias africanas, sem possibilidades econômicas para viagens de estudo, essas mulheres vivem num mundo limitado, mal pensam no conhecido para além do horizonte, procurando enraizar-se num ambiente que as repele, porque é evidente que os trópicos repelem o europeu [...] (ARCHER, 1963, p. 144).

Some-se a isso "o seu destino de mulheres pobres, normalmente destituídas de beleza, (que a África é ladra da beleza da mulher branca) [...]. São frágeis de saúde, flores de pouco viço ou perfume" (ARCHER, 1963, p. 144-145).

Antes da tentação de acusar a escritora - ela mesma uma dessas emigradas, sempre a invocar a própria experiência de colono para conferir legitimidade ao seu discurso - de estar simplesmente advogando em favor dos de sua "raça", cumpre dizer que logo na sequência transita para um tom de ácida ironia ao narrar a vida da branca rica, esposa de altos funcionários e residentes na capital.

Mantidas com conforto, vivendo com abundância e alegria, sentindo o futuro assegurado, viajando de quando em quando pelos climas frios, estas mulheres conservam a saúde e a beleza mesmo com muitos anos de permanência em África (ARCHER, 1963, p. 155).

Essa elite, proveniente da pequena burguesia que enriqueceu na colônia e que vive de modo fútil, não é poupada ao ser retratada com foco quase que exclusivamente sobre tais aspectos, com destaque para suas "maneiras e costumes de mau gosto" (ARCHER, 1963, p. 162). Poderiamos dizer que esse julgamento de valor a respeito do "mau gosto" das madames provém, em grande medida, do "fora de lugar" que as práticas desse café-society adquirem em Angola: 
Tomam o chá em casa da madame Soares. Bridge, pif-paf, canastra whisky, cigarros americanos, muitos modos vampirescos e exclamações no inglês ouvido no cinema:

- I am sorry, dear.

Combinam a caçada do domingo. Irão às pacaças? Quantos automóveis? Dez carros? Quem prepara o almoço? Ou pic-nic? E quem se convida? (ARCHER, 1963, p. 159-160).

Por fim, considerando que as brancas nascidas na África e as mestiças, id est, as classes mais pobres, tem a tendência de imitar a elite, Archer culpabiliza a classe abastada, alienada, de prestar um desserviço à causa da mulher portuguesa na colônia, uma vez que "dão mau exemplo" às demais.

\section{EM JEITO de CONCLUSÃo}

É patente que a produção de conhecimentos e a reflexão sobre o império do ultramar é marcada pela voz hegemônica do homem. Por mais revolucionárias que pudessem ser suas ideias e posturas, Maria Archer não poderia deixar de ser uma mulher do seu tempo (como, aliás, nenhum de nós pode). Se demonstrou empatia com o negro e com a situação da mulher de qualquer cor na colônia, não colocou em relevo "apenas" a natureza emotiva, chave pela qual tanto se julga a mulher e sua literatura como produção de menor valor, antes o fez de modo a problematizar a situação no cruzamento de saberes que penetraram "os terrenos da história, da etnografia, da política, da geografia, da literatura autobiográfica, da ficção etc." (MARTINS, 2005, p. 88).

Se assumiu as pretensões do discurso hegemônico de seu tempo, como quer Martins (2005, p. 89), promovendo as ideias civilizadoras eurocêntricas, e mais ainda, portuguesas, dos "únicos herdeiros diretos da tática romana de assimilação dos povos conquistados" (ARCHER, 1963, p. 142-143), é também verdade que o fez a partir de um locus enunciativo diverso, do lugar da mulher. O olhar "quase" científico da escritora, talvez justamente pelo seu caráter autobiográfico e híbrido, somado à sua experiência empírica na colônia, à sua consciência de ser não uma mera observadora, mas um colono, imprimem em seus textos um tom único em meio ao universo iminentemente masculino que dominou a cena da Literatura Colonial.

\section{The Portuguese-African-Brazilian world of Maria Archer: a look at Brasil, FRONTEIRA DA ÁFRICA}

Abstract: This essay intends to observe the way writer Maria Archer's speech (1899-1982), a nonstandard woman for the Portuguese patterns of the New State, sometimes promotes either the maintenance or ruptures under the imperialist vision and policy of the Salazar regime in the overseas colonies, furthermore contributing to the construction of the imaginary about Africa in Portugal and in Brazil. It will be particularly emphasized the ways in which the writer sees and analyzes the presence of women in the social landscape of Angola and Mozambique, according to the book Brasil, fronteira da África, from 1963. 
Keywords: Maria Archer. Brasil, fronteira da África. Colonial literature.

\section{REFERÊNCIAS}

ARCHER, M. Revisão de Conceitos Antiquados. Ler, Lisboa, n. 7, out. 1952.

ARCHER, M. Brasil, fronteira da África. São Paulo: Felman-Rego, 1963.

BEAUVOIR, S. de. O Segundo Sexo. 1. Fatos e Mitos. Tradução Sérgio Milliet. Rio de Janeiro: Nova Fronteira, 1980.

BONNICI, T. O pós-colonialismo e a literatura: estratégias de leitura. Maringá: Editora da Universidade Estadual de Maringá, 2000.

DU PLESSIS, R. B. Writing beyond the ending: narrative strategies of twentiethcentury women writers. Bloomington: Indiana University Press, 1985.

FANON, F. Pele Negra Máscaras Brancas. Tradução Alexandre Pomar. Porto: Paisagem, 1975.

FREYRE, G. Prefácio. In: ARCHER, M. Herança Lusiada. Lisboa: Edições Sousa e Costa, 1954?. p. 9-11.

MANCEAUX, M. As mulheres de Moçambique. Tradução Manuel João Gomes. Lisboa: Arcádia, 1976.

MARTINS, L. P. Menina e moça em África: Maria Archer e a Literatura Colonial Portuguesa. Lusotopie, v. 12, n. 1-2, 2005. Disponivel em: <https://lusotopie. revues.org/1183\#text>. Acesso em: 6 abr. 2017.

MEMMI, A. Retrato do colonizado precedido pelo retrato do colonizador. Tradução Roland Corbisier e Mariza Pinto Coelho. Rio de Janeiro: Paz e Terra, 1977. SPIVAK, G. C. Quem reivindica a alteridade?. In: BUARQUE DE HOLLANDA, H. (Org.). Tendências e impasses: o feminismo como crítica da cultura. Rio de Janeiro: Rocco, 1994. p. 187-205.

Recebido em dezembro de 2015. Aprovado em fevereiro de 2016. 